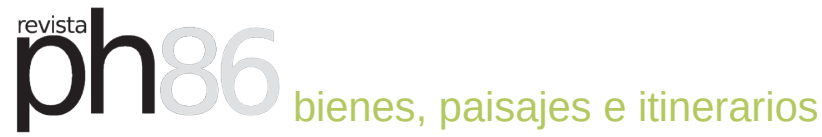

\section{Las rutas culturales de los Pedroches}

Asociación ADROCHES para el Desarrollo Rural de Los Pedroches

URL de la contribución <www.iaph.es/revistaph/index.php/revistaph/article/view/3502>

\section{RESUMEN}

La comarca de los Pedroches se encuentra situada en el norte de la provincia de Córdoba, tierra fronteriza entre Andalucía, Castilla la Mancha y Extremadura; situación privilegiada que dota este territorio de una amplia variedad de matices su paisaje, cultura, gastronomía y patrimonio. Integrada por 17 municipios, es la comarca más extensa de Andalucía. Todos ellos conforman una unidad, tanto ecológica como cultural, que le da consideración de comarca natural.

Su ubicación geográfica -frontera con las provincias de Badajoz y Ciudad Real-, unida a sus características físicas -el batolito que cruza la comarca, materia prima para las construcciones de granito de la zona-, la semejanza paisajística -tierras de dehesa-, y la explotación de los recursos, contribuyen a establecer vínculos entre los Pedroches, la comarca extremeña de la Serena y la castellano manchega de Alcudia.

\section{Palabras clave}

Andalucía | Córdoba (Provincia) | Dehesas | Gastronomía | Patrimonio cultural | Patrimonio natural | Rutas culturales | Valle de los Pedroches (Córdoba) | 


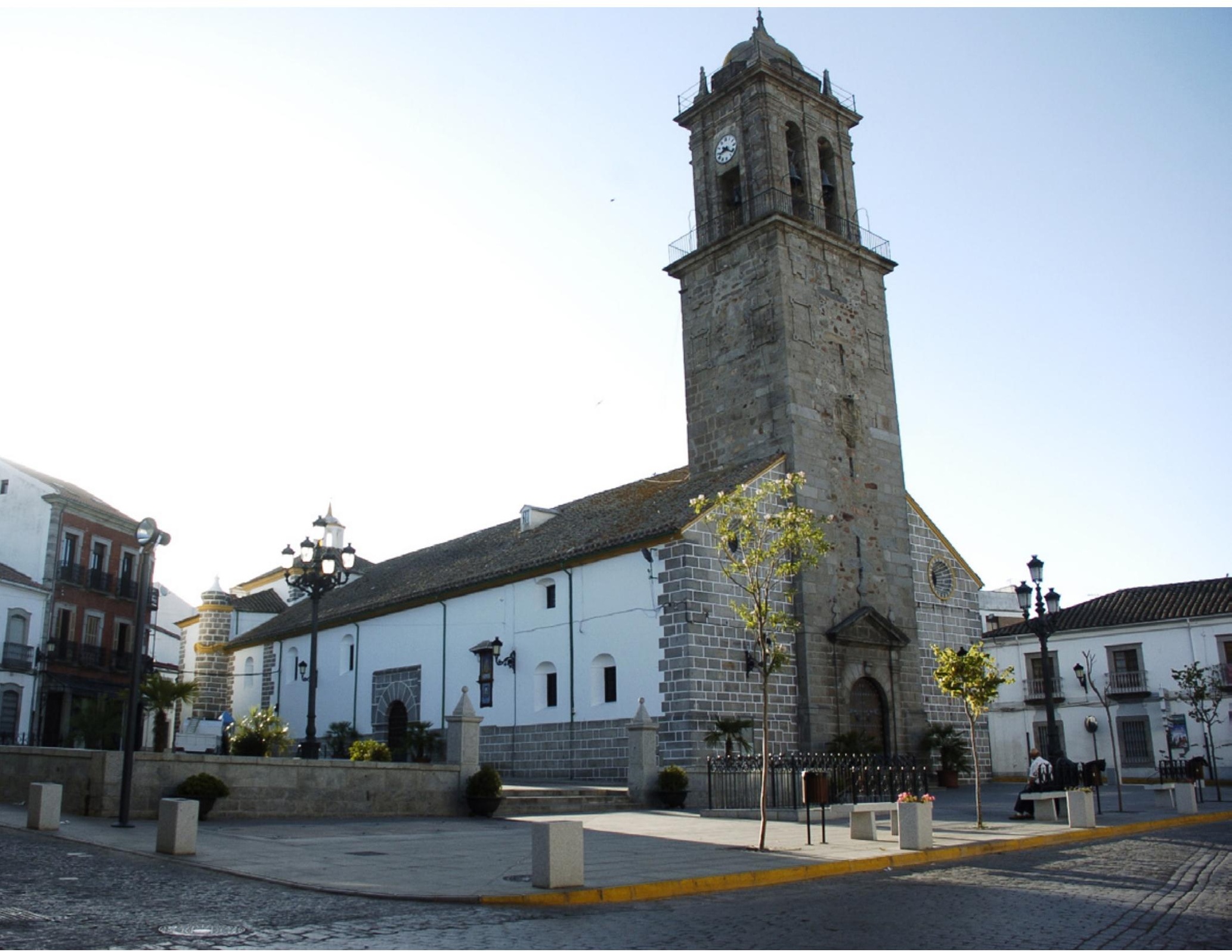

Parroquia de San Miguel. Villanueva de Córdoba | fuente Fondo fotográfico de la Asociación ADROCHES (para todas las imágenes del artículo) 


\section{VÍAS PECUARIAS, CAÑADAS REALES Y LOS CORDELES}

Su situación geográfica, como zona intermedia entre Andalucía, Castilla la Mancha y Extremadura, acentúa su carácter de territorio de frontera histórico-cultural, a la que ha contribuido de forma predominante su condición de paso obligado en las antiguas comunicaciones entre la meseta y Andalucía. Según los estudios realizados, esta circunstancia se daría desde las primeras edades del hombre, aunque fue durante el periodo califal cuando esta condición de lugar de tránsito adquiere mayor relevancia, puesto que el camino que unía Córdoba y Toledo atravesaba los Pedroches.

Este camino aprovechaba en parte una antigua calzada romana, y era imprescindible en el desplazamiento de las zonas atlánticas y levantinas con el eje central de la Península. Como prueba de ello, podemos encontrar todavía hoy restos de antiguos caminos, como la cañada real soriana o la cañada real de la Mesta, testigos de la trashumancia y el transporte de mercancías, así como las antiguas posadas y fondas que daban cobijo a los viajeros, como la antigua posada del Moro en Torrecampo.

Sirvieron para la comunicación de hombres y culturas. Gracias a los movimientos pecuarios, comarcas aisladas como los Pedroches o el valle de Alcudia, recogieron aspectos etnográficos que hicieron propios y que aun perviven en las tradiciones locales, demostrándonos que la identidad actual es heredera de una relación entre pueblos.

La gastronomía y el folclore son para el visitante testimonio de la riqueza de matices de una tierra fronteriza, demostrando en sus platos -dónde predominan los derivados del cerdo ibérico- $y$ en sus tradiciones, claramente influenciados por el paisaje, sus usos y aprovechamientos, la personalidad que hace única esta comarca cordobesa.

Paisaje de dehesa

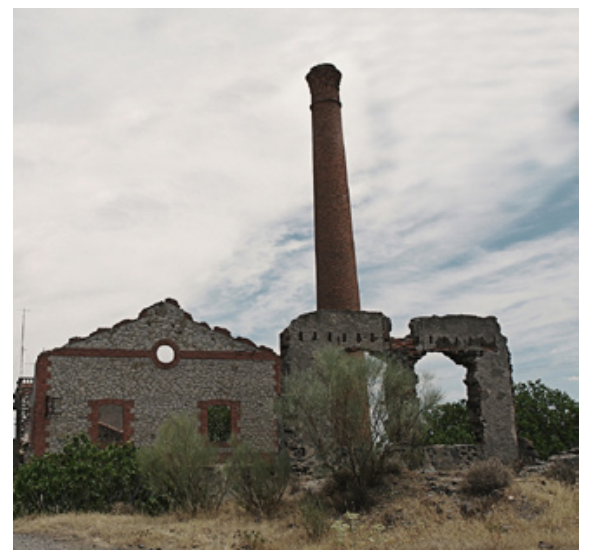

Minas del Soldado. Villanueva del Duque

Los restos arqueológicos que se distribuyen a lo largo y ancho de su territorio, nos hablan de la importancia de los antiguos asentamientos existentes en la comarca desde muy antiguo, destacando las actividades mineras y ganaderas como la base de su economía. Fue enclave de importancia en la época romana, algo constatado en el yacimiento de Majadaiglesia, urbe con relevante papel en la agricultura, ganadería y minería.

La riqueza mineral de los Pedroches ha sido aprovechada por las civilizaciones que han habitado en ella. Buena parte de la cañada real soriana se funde con la vía romana del Azogue, por dónde se llevaba el mercurio desde las minas de Almadén hasta Córdoba, la entonces capital de la Bética. A tener en cuenta las minas del Soldado y las Morras, que dieron esplendor y riqueza a la comarca en las primeras décadas del siglo $\mathrm{XX}$. 


\section{LOS PEDROCHES EN LA ÉPOCA MODERNA}

Todos los pueblos que habitaron este territorio dejaron su impronta de una $u$ otra manera, permitiéndonos en la actualidad el poder disfrutar de los monumentos, paisajes o tradiciones que han pervivido en el territorio.

Su aprovechamiento económico a lo largo de los siglos, nos ha proporcionado un rico patrimonio arquitectónico rural y monumental, que se muestra a través de norias, chozas, fuentes, abrevaderos diseminados por la dehesa, además de ermitas, casas con escudos blasonados, torres y castillos que dominan los flancos de la comarca al norte, oeste y centro, siendo el granito la materia prima que sobrevive al paso del tiempo.

Tras la reconquista, ya en el siglo XIII, se produjo una reorganización administrativa que dio lugar a la aparición de tres subcomarcas, que hoy día constituyen rutas de carácter cultural afianzadas en el territorio.

La ruta de las Siete Villas, conformada por los municipios de Dos Torres (Torremilano), Torrecampo, Pozoblanco, Villanueva de Córdoba, Alcaracejos y Añora, y encabezados por Pedroche, ofrece al visitante un interesante patrimonio natural e histórico artístico. Estas villas de realengo dependieron siempre de la jurisdicción de Córdoba, y pudieron hacer frente a los grandes señores gracias a la unidad que demostraron, manteniendo un único término juridisccional hasta 1909, así como el aprovechamiento comunal de grandes extensiones de dehesa, como la de la Jara, la de Ruices o la dehesa de las Navas del Emperador. El gestionar y compartir el principal recurso natural marcó los vínculos políticos de estas poblaciones. El concejo se reunía en la ermita de Piedrasanta, donde hasta el año pasado podían verse los bancos donde se sentaban los representantes de los concejos. En el año 2013 se inauguró el Centro de Interpretación de las Siete Villas de los Pedroches ubicado en el mismo paraje donde se encuentra la ermita, y construido con el propósito de difundir la historia común de las Siete Villas, desde el siglo XIII hasta el XIX, dándonos a conocer su origen, su organización política e institucional y la cultura tradicional surgida de ella.

El pasado medieval de la villa de Pedroche queda patente en su entramado urbano, cuyas calles en su día formaron parte de la antigua judería. Como prueba de su pasado de esplendor han quedado ermitas como la de San Sebastián, la iglesia conventual de la Inmaculada Concepción, monasterio fundado en el siglo XVI o Santa María del Castillo.

Torrecampo fue una de las poblaciones surgidas al amparo de Pedroche, cuando sus habitantes huyeron de la peste que asolaba el pueblo. De origen medieval, sigue manteniendo viva en la actualidad su dedicación a la agricul- 


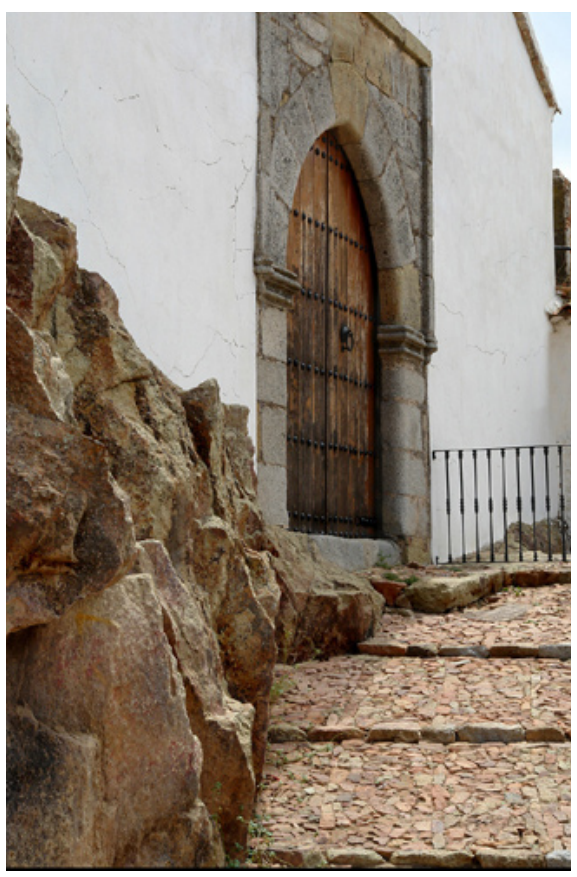

Iglesia del Salvador. Pedroche

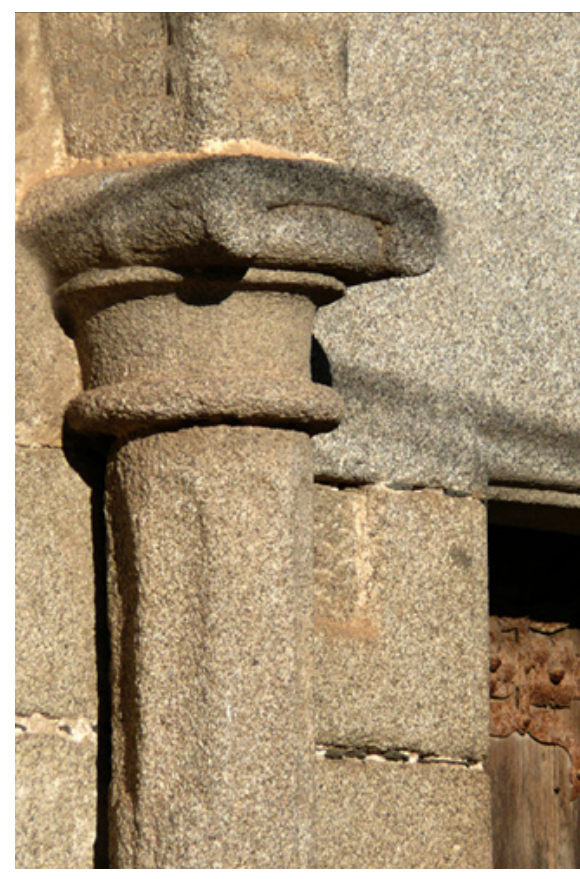

Posada del Moro. Torrecampo

tura y a la ganadería, conservando los rasgos de lugar de paso de las rutas de la trashumancia.

Los orígenes de Dos Torres se remontan a los siglos XIV y XV, ya que fue en éstos en los que surgieron las dos villas que dieron lugar con el paso del tiempo al actual municipio: Torremilano y Torrefranca. Fue el 11 de diciembre de 1839 cuando el general Espartero decretó la fusión en un sólo municipio de las dos villas: Dos Torres. Estas villas fueron cuna de nobles e hidalgos, rango social que ha quedado patente a través de los siglos en sus monumentos y casas solariegas de portadas y escudos blasonados, conservando uno de los más importantes legados arquitectónicos de los existentes en la zona.

Es probable que el nacimiento de Villaralto a comienzos del siglo XV se relacione con el pago de viñas y tierras de pastoreo de gentes de Torremilano, que construyeron varias chozas para cuidar más de cerca sus heredades, surgiendo como núcleo permanente a finales del siglo $\mathrm{XV}$ o principios del $X V I$, reconocido en sus inicios como barrio dependiente de Torremilano. Cabe destacar la existencia de un museo del Pastor, institución creada con la finalidad de proteger, conservar y difundir el patrimonio etnológico relacionado con la vida pastoril de la comarca, y especialmente de la localidad.

El puerto del Calatraveño, insignia y emblema de la zona, marca la entrada natural al sur de los Pedroches. Singulares paisajes ofrecen los ríos Cuzna y Guadalbarbo. Vigilado por la Chimorra, inquebrantable testigo de un esplen- 
doroso pasado minero, Alcaracejos aparece como testigo del paso del visitante por importantes vías de comunicación que contrastan con el granito y cal de sus calles. En el término tienen cabida los cuatro paisajes fundamentales de los Pedroches: cereal, zonas de olivar, dehesas ganaderas y monte mediterráneo.

El término "añora" tiene su origen en la palabra árabe naura, que significa noria. Según los estudiosos, el término hace referencia a la noria de una huerta que había en las cercanías del lugar que, actualmente, ocupa el municipio. Y fue en torno a la huerta citada donde se fueron agrupando los habitantes primeros de la villa.

Como segundo gran espacio histórico, que conforma parte del territorio de los Pedroches, encontramos la ruta del Condado de Santa Eufemia, que comprende los municipios de Santa Eufemia, El Guijo, El Viso y Torrefranca. Surgido en 1293, cuando el concejo cordobés hace donación a Fernando Díaz Carrillo de la villa de Santa Eufemia, lo que propició la creación de éste Condado, ya que por sus tierras transcurría una de las principales vías de comunicación en el transporte de mineral desde Almadén hasta Córdoba y Sevilla, la denominada ruta del Azogue.

Santa Eufemia ha sido a través de los siglos puerta natural de entrada a los Pedroches. Su carácter fronterizo le ha otorgado igualmente una privilegiada posición estratégica. El intenso pasado medieval de Santa Eufemia todavía se aprecia, además de en la iglesia, en la propia configuración urbana de la población y particularmente en su cerco de murallas. Uno de los elementos patrimoniales más singulares de Santa Eufemia es el castillo de Miramontes, antigua fortaleza musulmana desde la que se pueden contemplar los paisajes de Extremadura, Castilla la Mancha y Andalucía.

Del esplendor romano de esas tierras dan buena prueba los restos arqueológicos aparecidos en la zona de Majadaiglesia, en el municipio de El Guijo, un área de fuerte tradición mariana como demuestran documentos castellanos del siglo XII. En este enclave conocido como "El Soto" se encuentra también la ermita de la Virgen de las Cruces, a 6 kilómetros del casco urbano. Construida sobre el cordel de la Mesta; en la sacristía se puede contemplar un baptisterio de origen paleocristiano.

La primera mención documentada de El Viso data del año 1410, donde aparece con el nombre de Casas de Don Adame, cuyo origen pudo deberse al establecimiento de unas ventas en la ruta que comunicaba Castilla con Andalucía. Su término ha sido siempre paso obligado en el "camino del Azogue". Bajo la jurisdicción del condado de Santa Eufemia, hasta el siglo XIX, El Viso se convirtió en la localidad más poblada del

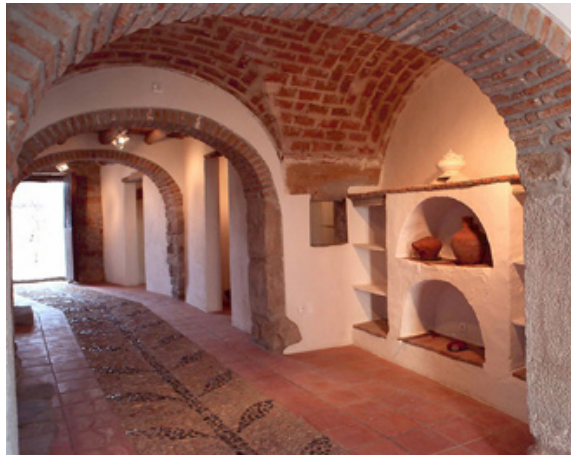

Museo del Pastor. Villaralto

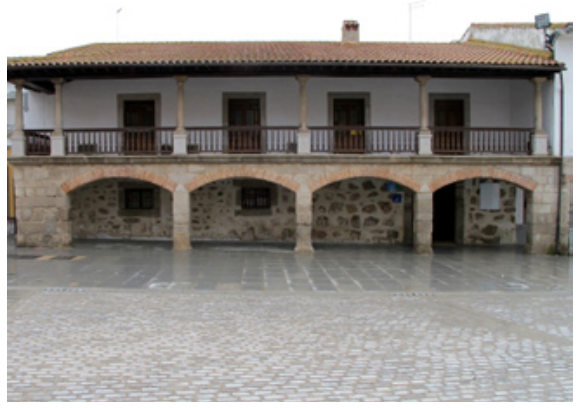

Plaza porticada. Dos Torres

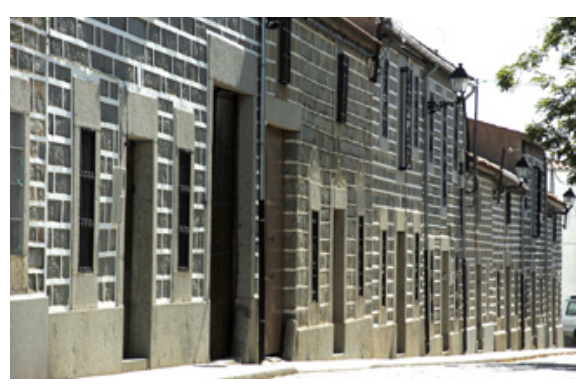

Fachadas de tiras. Añora

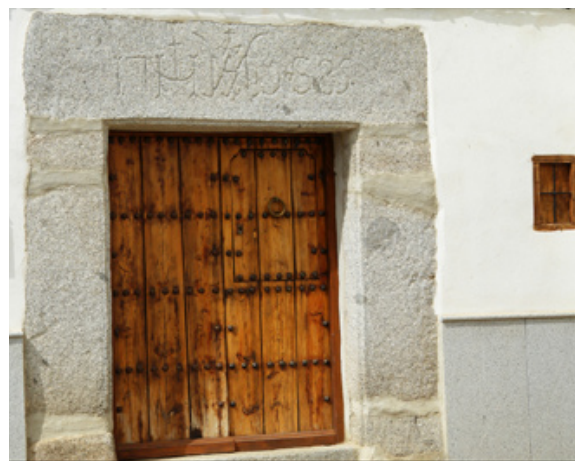

Dintel de granito. Alcaracejos citado señorío. El Viso también conserva en su término el conocido como 


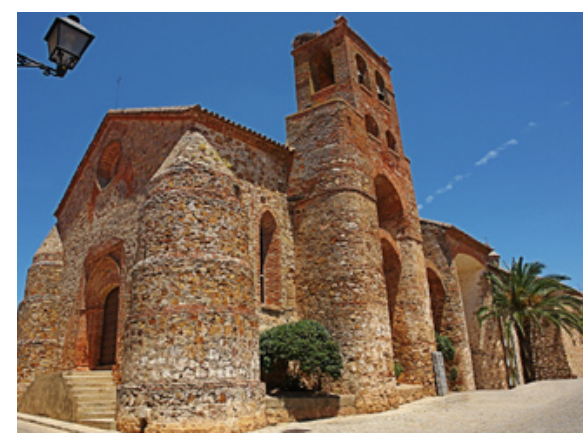

Parroquia de Ntra. Sra. De la Encarnación. Santa Eufemia

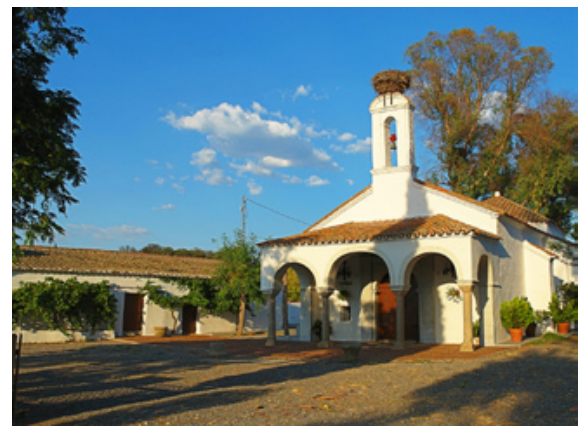

Virgen de las Cruces. El Guijo

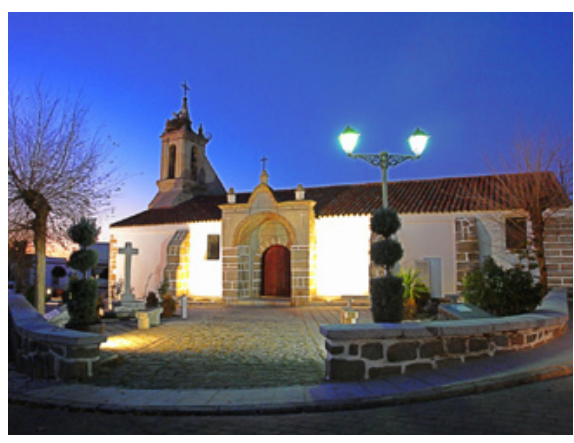

Parroquia de Santa Catalina. Fuente la Lancha

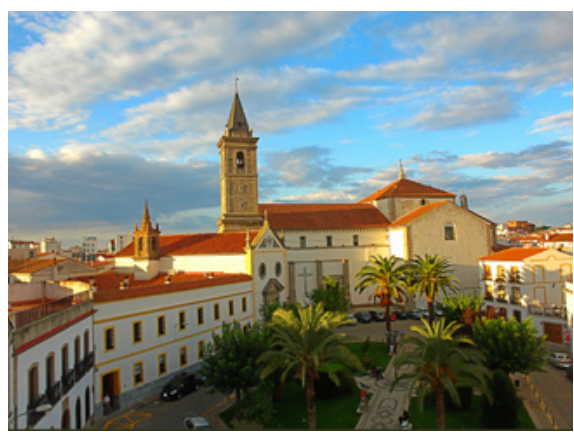

Parroquia de Santa Catalina. Pozoblanco

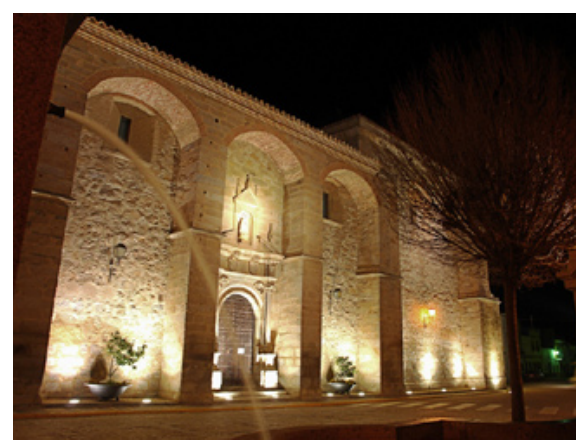

Convento de las Concepcionistas. Hinojosa del Duque

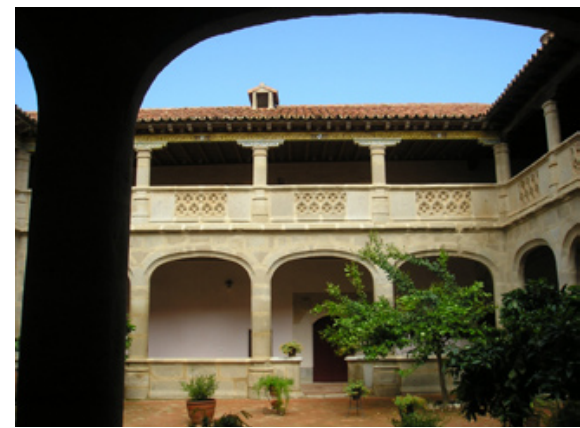

Convento de Santa Clara. Belalcázar

castillo de Madroñiz, de origen musulmán, bien conservado y visitado habitualmente por cazadores.

El condado de Belalcázar, se originó en 1445, cuando Juan II concedió al entonces maestre de la Orden de Alcántara, las Villas de Gaete (Belalcázar) e Hinojosa del Duque; a éste condado también pertenecían las villas de Villanueva del Duque y Fuente La Lancha.

La comarca de los Pedroches no deja indiferente al visitante ante la riqueza monumental escondida en las callejas de sus pueblos, construcciones de dimensiones espectaculares como el Convento de Santa Clara de Belalcázar, segundo monumento histórico-artístico tras la Mezquita de Córdoba, o el imponente castillo de los Sotomayor, también en Belalcázar, guardián de los Pedroches desde la Serena, del que destaca su torre del homenaje de $45 \mathrm{~m}$ de altura.

Hinojosa del Duque ofrece uno de los conjuntos monumentales más notables del norte de la provincia de Córdoba. Vinculada a la casa condal de Belalcázar desde 1444, se convirtió en el municipio más importante del citado señorío. Fue durante siglos parada obligada para los pastores trashumantes y centro de las ferias de ganado, de lo que es testigo su fuente del Pilar. Villanueva del Duque se creó a finales del siglo XV. Su primitivo 
nombre fue Villanueva del Marqués, que cambió por el actual después que en 1518 se vinculase al condado de Belalcázar el ducado de Béjar. La intensa actividad minera que se desarrolló en el siglo XIX en su término dio lugar a la creación de poblados con una importante población y actividad económica.

Aldea de Hinojosa del Duque hasta 1820 cuando consiguió el título de villa, Fuente la Lancha, constituye el municipio con menor extensión de la comarca, lo que siempre ha limitado su extensión. El origen del topónimo "lancha" puede proceder del nombre dado a las piedras de granito de forma plana que afloran a la superficie.

\section{DEHESAS E IBÉRICO}

La última de las rutas que podemos destacar en los Pedroches, y que constituye hoy en día uno de los principales recursos de la población, es la denominada ruta del Ibérico. La importancia ganadera de los Pedroches se desarrolla desde la época árabe cuando recibió el nombre de Fash al-Ballut (llano de las bellotas), y que constituye una de las mayores riquezas de la zona: el jamón ibérico de bellota.

El pastoreo de los cerdos ibéricos en la dehesa configura una estampa única durante la época de montanera a finales de otoño, pasando por las matanzas de las que se obtienen los jamones y paletas de ibérico que se destacan en su gastronomía, lo que constituye uno de los mayores reclamos turísticos de la comarca.

En los últimos tiempos se están potenciando estos rituales culinarios como atractivo para el turismo activo, haciendo partícipe al visitante de este proceso de elaboración artesanal de uno de los platos por excelencia de la gastronomía de los Pedroches.

Recorriendo la ruta del Ibérico podremos conocer el entorno donde se cría el cerdo ibérico, la diversidad de los paisajes que integran la ruta y la actividad y patrimonio de sus pueblos. Desde Hinojosa y Alcaracejos, Ilegando a Pozoblanco y Villanueva de Córdoba, y finalizando en Cardeña o Conquista, recorremos los pueblos en los que de forma más significativa se ha desarrollado tradicionalmente la producción e industria del ibérico.

Su posición geográfica en el centro de los Pedroches ha convertido a Pozoblanco en la capital económica y administrativa de la comarca. Su patrimonio está lleno de elementos originales que guardan una belleza heterogénea dentro de su sencillez, siendo denominador común de todos ellos el granito. La personalidad emprendedora de su gente no está reñida con el 


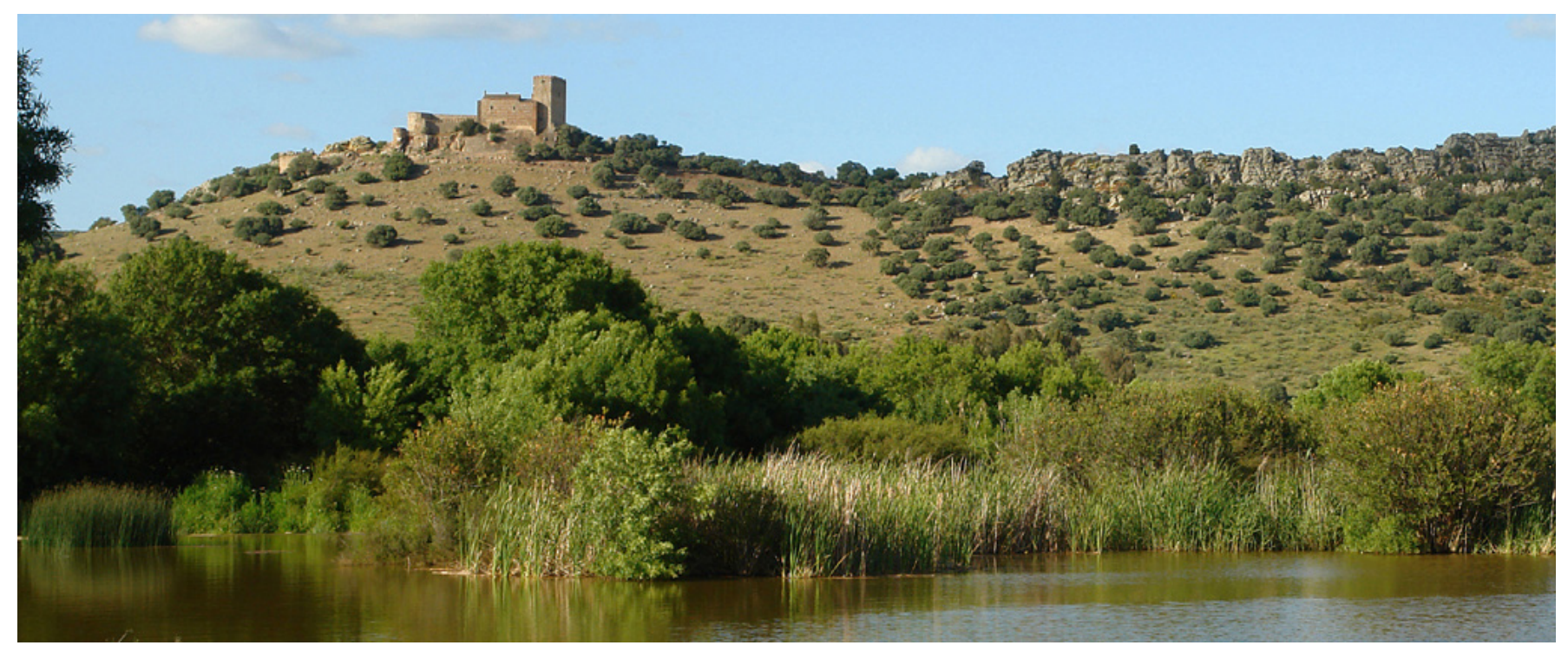

Castillo de Madroñiz. El Viso

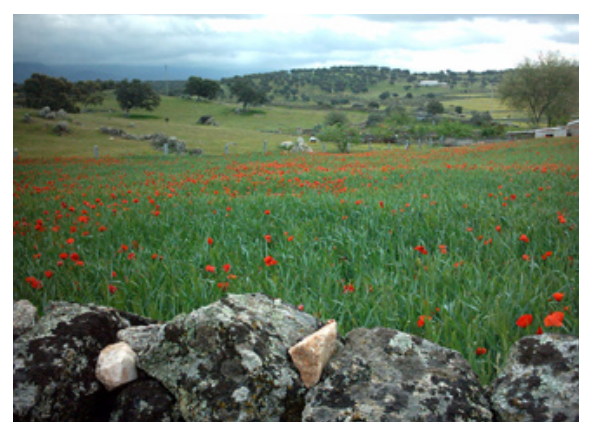

mantenimiento del sabor a pueblo de la sierra que ha sabido preservar su entorno natural, donde la dehesa de encinar en la que pasta el cerdo ibérico da paso a la abruptosidad y riqueza biológica del ecosistema del río Cuzna.

El desarrollo ganadero pasa a ser la principal fuente de riqueza de la localidad de Villanueva de Córdoba; muestra de ello es la extensa dehesa que la rodea, que es considerada el bosque de encinar más extenso de Europa, y donde se ceban los cerdos ibéricos, cuyos productos derivados -jamón, cecinas,...- encuentran en este municipio el lugar perfecto para su curación.

Paredes de granito. Conquista

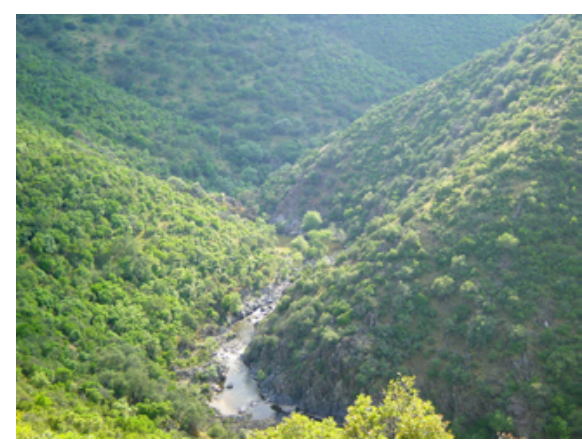

Río Yeguas. Cardeña
El municipio de Conquista nació en torno al camino de la Plata, que unía Córdoba con Toledo, aunque no alcanzaría su esplendor hasta finales del siglo XIX y en las primeras décadas del XX, debido a las explotaciones mineras y a la llegada del ferrocarril. Las espesas y frondosas dehesas de encinar en sus alrededores dan muestra del marcado carácter ganadero de esta localidad.

El municipio de Cardeña presume de contar con uno de los paisajes mejor conservados de Sierra Morena. No en vano, la mayor parte del Parque Natural de Cardeña-Montoro se ubica en su término municipal. Situada en uno de los caminos utilizados para llegar a Toledo desde Córdoba, diversos privilegios reales dieron origen a una serie de ventas en esta zona, circunstancia que explica el nacimiento de Cardeña, Azuel y Venta del Charco. 


\section{BIBLIOGRAFÍA}

- Domínguez, F. J. (2008) Dehesas y la trashumancia en el Sur: Las fronteras de Andalucía. Dos Torres. Córdoba: Asociación ADROCHES para el Desarrollo Rural de la Comarca de Los Pedroches, 2008

- Memoria ADROCHES 2000-2008. Grupo de Desarrollo Rural de Los Pedroches, 2009

- LUNA, M.; LUCAS, M. (2006) Arquitectura tradicional y entorno construido. Proyecto Identidades II. Asociación ADROCHES para el Desarrollo Rural de la Comarca de Los Pedroches, 2006.

- VAlLE Buenestado, B. (1985) Geografía Agraria de Los Pedroches. Córdoba: Diputación Provincial de Córdoba, 1985

- CARPIO DUEÑAS, J. B. (2000) La tierra de Córdoba. El dominio jurisdiccional de la ciudad durante la Baja Edad Media. Córdoba: Publicaciones de la Universidad de Córdoba y Obra Social y Cultural CajaSur, 2000 